Revista Iberoamericana, Vol. LXXVI, Núm. 230, Enero-Marzo 2010, 153-168

\title{
LAS NUEVAS VOCES TESTIMONIALES Y REIVINDICATIVAS DEL INTELECTUAL AFRO-LATINOAMERICANO EN EL BRASIL: EL GRUPO QUILOMBHOJE
}

\author{
POR \\ LizBETH SOUZA-FueRTES \\ Baylor University
}

Cuando a finales de la década de los 70 se gesta, bajo la dirección del escritor brasileño de origen africano Cuti (pseudónimo de Luiz Silva), la fundación del grupo Quilombhoje, se ponen también las bases de un nuevo movimiento, a la vez crítico y testimonial, que va a dar voz a aquellos escritores negros profundamente críticos hacia las valoraciones dominantes en la sociedad brasileña en relación con la problemática racial. Al mismo tiempo que cuestionan el mito de la democracia racial, testimonian una realidad de discriminación, más o menos encubierta, sufrida por el afrobrasileño en la sociedad a todos los niveles.

Quilombhoje como grupo nace en 1980 y estará integrado en su fase inicial por Cuti, Oswaldo de Camargo, Abelardo Rodrigues, Paulo Colina y el escritor argentino Mario Jorge Lescano. Surge con la finalidad específica de dar a conocer a la comunidad negra del Brasil la realidad auténtica en la que se mueve y, sobre todo, de ofrecer la oportunidad de debatir de forma pública y abierta los posicionamientos de los intelectuales negros. Se trata, verdaderamente, del componente literario de esa amplia movilización cultural que constituyó el Movimento Negro Nacional, que alentó la unión entre organizaciones afrobrasileñas y se enfrentó a toda forma de discriminación. Los primeros objetivos del grupo se verán ampliados con la organización de importantes proyectos culturales, entre los cuales se destacan recitales poéticos y debates sobre literatura, a la vez que se enriquecen con las aportaciones de las nuevas generaciones de jóvenes poetas y narradores. Muy pronto, incluso en la misma década de los 80 , se incorporarían al grupo escritores tan relevantes como Miriam Alves, José Alberto, Márcio Barbosa, Oubi Inaê Kibuko, Esmeralda Ribeiro, Sônia Fátima da Conceição y Jamu Minka, que marcarían los nuevos caminos del grupo y, en general, de la literatura negra en el Brasil. Además, como relevo generacional, se encargarán tanto de los nuevos proyectos, como de continuar la labor iniciada por Cuti y Hugo Ferreira, al fundar los Cadernos Negros en 1978. Esa revista ha permitido a los escritores negros brasileños dar a conocer su obra tanto poética como cuentística. No se podría entender el movimiento Quilombhoje 
y el resurgimiento literario del mundo negro en el Brasil contemporáneo sin esta revista que, durante casi 30 años, ha sido, con demasiada frecuencia, casi el único medio del que ha dispuesto el escritor negro brasileño para publicar su obra.

Como grupo, Quilombhoje se vertebra en una doble vertiente: por un lado, como movimiento reivindicativo con un fuerte componente sociológico y, por otro, como creación artística pura y renovadora del lenguaje. Ambas líneas están dominadas por un marcado tinte racial y mediatizadas por la constatación de la tendencia en la literatura brasileña a enmascarar la realidad del racismo y la subvaloración de la presencia africana. Además de su lucha contra el racismo y todas aquellas formas más o menos encubiertas de discriminación, su objetivo primordial consistirá en la búsqueda de nuevos caminos expresivos que les permita crear una literatura que sea capaz de romper con los modelos blancos y liberarse de todo tipo de dependencias, tanto culturales como artísticas. O sea, una literatura planteada desde la perspectiva negra y para el lector negro.

El objetivo de este trabajo consiste en estudiar las características que definen el grupo Quilombhoje, así como las nuevas formas que se proponen introducir en su escritura en el proceso de reivindicación de la literatura negra, partiendo siempre de un claro enfrentamiento con los mitos raciales y los modelos más reaccionarios del pensamiento brasileño, con una clara intención de transcender el campo del racismo para involucrarse en el propio tema de la identidad del pueblo brasileño. Aunque las perspectivas personales, la calidad literaria y los objetivos de los integrantes de Quilombhoje no sean siempre coincidentes, hay una serie de campos temáticos y proyectos comunes que le comunican una indudable unidad. Por ejemplo, la concientización y enfrentamiento al racismo, la búsqueda de la identidad del afrobrasileño y su proyección en la propia identidad del Brasil, la perspectiva crítica que trata de desmontar mitos raciales profundamente enraizados en la sociedad -como el de la democracia racial-y la firme postura de reivindicar su imagen y enfrentarse a la manipulación histórica que ha sufrido el mundo negro. Estos objetivos y planteamientos forman parte de un largo proceso que se inicia con la obra de João da Cruz e Sousa a finales del siglo diecinueve y tendrá como puntos de referencia básicos en el siglo veinte la obra de Lino Guedes y Solano Trindade, para finalmente, con el proyecto Quilombhoje, aglutinar y armonizar los más destacados posicionamientos de confrontación con una visión conservadora de las relaciones raciales, sustentadas, sobre todo, en la obra de Gilberto Freyre, Casa grande e senzala (1933), que desde la década de los 30 ha puesto las bases de la ideología de la democracia racial, sustentadora y justificadora del status quo y de la dominación blanca. La conciencia oligárquica brasileña recibe un fuerte impulso con la aparición de esta obra, que contribuye a crear una falsa realidad en la cual las relaciones raciales, si no idílicas, al menos se consideran aceptables en el Brasil.

Revista Iberoamericana, Vol. LXXVI, Núm. 230, Enero-Marzo 2010, 153-168
ISSN 2154-4794 (Electrónico) 
Esta mitificación de la realidad ha sido atacada en tres frentes, fundamentalmente en el mundo intelectual contemporáneo brasileño. En primer lugar, por los pensadores de la Teología de la Liberación, sobre todo por Leonardo Boff; a ellos se uniría una minoría de intelectuales blancos, como Darcy Ribeiro y Antônio Callado, que se han enfrentado en su obra a la problemática de la integración de las minorías; y, finalmente, por el grupo Quilombhoje.

Todos ellos contemplan el fenómeno del racismo como una manifestación continental, coincidiendo en subrayar la profunda hipocresía con la que se encara este tema. Gustavo Gutiérrez, como representante más destacado de la Teología de la Liberación, señala que "una de nuestras mentiras sociales es afirmar que en Latinoamérica no hay racismo. Tal vez no haya leyes racistas como en otros países, pero sí existen costumbres racistas hondamente acendradas, hecho no por soterrado menos grave” (23). Cuti, el más representativo de los escritores del grupo Quilombhoje, en la misma línea matiza esta idea al aplicarla a la realidad brasileña, afirmando: "é preciso dizer que o racismo brasileiro é o racismo mais eficaz do mundo, é o racismo mais eficaz do mundo inteiro porque ele se baseia numa hipocrisia refinada" ("Uma entrevista” 902). Al fundamentarse en el concepto de la democracia racial, mediante el cual Gilberto Freyre, como creador, y todos sus seguidores -nos explica Cuti- han logrado un doble resultado: por un lado, dificultar la tarea de combatir el racismo, ya que gracias a esa ideología "a elite brasileira vendeu para o mundo a idéia de que aqui não há preconceito, de que aqui não há discriminação racial” (“Uma entrevista” 902-03). Por otro lado, impidió que los negros percibieran esa intensa discriminación que sufrían al hacer que "introjetassem a discriminação, de uma maneira que não fossem receptivos a uma mensagem diferente" (“Uma entrevista” 903).

En su obra, Cuti -quien marcaría muchos de los caminos seguidos por los miembros de Quilombhoje en el tratamiento del tema del racismo-, al incidir una y otra vez en la crítica de la ideología que niega el racismo en el país, le otorga un indudable protagonismo y revela hasta qué nivel ha calado su nocivo mensaje en la cultura brasileña, al encubrir formas discriminatorias o puramente racistas. De ahí su insistencia en el desenmascaramiento del racismo en todas sus manifestaciones, siempre recalcando la omnipresencia del mismo y sus perniciosos efectos en la sociedad. Como consecuencia, tanto su obra poética, como la teatral y la narrativa, se proyectará siempre sobre el plano de fondo de una sociedad racista en la que el afrobrasileño será víctima de un amplio abanico de agresiones que impiden su plena realización como ser humano, al ahogar su "yo" más profundo y contribuir a transmitir imágenes estereotipadas cargadas de negatividad, que con demasiada frecuencia están asociadas con la pobreza, la violencia o la delincuencia.

La concepción de Cuti de la literatura como arma político-social-marcando una tendencia que se generalizaría en el grupo Quilombhoje- le comunica a su obra un

Revista Iberoamericana, Vol. LXXVI, Núm. 230, Enero-Marzo 2010, 153-168
ISSN 2154-4794 (Electrónico) 
carácter beligerante, que permite contemplar el racismo inserto en el contexto de la lucha de clases, en el que la creación literaria va unida a un intento de testimoniar críticamente el trasfondo sociológico que da origen a la discriminación. Esto quedará puesto de manifiesto claramente en su obra narrativa, en la que el afrobrasileño se contempla como víctima de estructuras sociales que favorecen o, al menos, hacen posible la existencia de un racismo generalizado. Sus narraciones nos muestran un Brasil sombrío y violento, como resultado de una mirada profunda y desencantada. En su intento por denunciar la opresiva realidad del racismo, situará al afrobrasileño en contextos que resalten los desafíos o acusaciones con las que se tiene que enfrentar constantemente. Sobre todo con aquella que lo acusa de ser una rémora para el país, temática que desarrollará en la narración “Ah, esses jovens brancos de terno e gravata”, donde se presenta al afrobrasileño como el chivo expiatorio de todos los males del país. Su protagonista será la víctima de los prejuicios raciales encarnados en una burguesía blanca que achaca el atraso social y económico a los negros. La reacción violenta del afrobrasileño ante los comentarios racistas de un joven ejecutivo blanco, que dice en público “O Brasil não vai pra frente por causa desses pretos e desses baianos. Essa gente é que é o nosso atraso. O governo devia acabar com todos eles” (Cuti, “Uma entrevista” 900) es el desencadenante de una tragedia al producirse la muerte del ejecutivo tras la agresión. Esta frase, en realidad, resume el sentir de la burguesía blanca y es un buen ejemplo de los mecanismos utilizados por las élites para eludir su responsabilidad histórica. El afrobrasileño ve arruinada su vida por enfrentarse a una de las grandes manipulaciones de la burguesía. Es una vez más su víctima. El autor refleja la indefensión legal y la violencia profunda, verbal y física que, en el fondo, tiene un origen racista (Cuti, "Una entrevista” 900).

Otra variante de esa realidad de discriminación a la que se somete a la comunidad negra la encontramos en el cuento, "Vida em dívida”, en la que se pone de manifiesto la pervivencia y poder de los prejuicios raciales. El asesinato de un niño negro de once años, como resultado del error cometido por un sicario que había sido contratado por un burgués para llevar a cabo una venganza en la persona del hermano mayor del joven asesinado, muestra una vez más los prejuicios raciales que alimentan las clases medias y altas del país, y es, a la vez, la demostración de la vileza moral en la que vive parte de la burguesía brasileña que llega a culpar al hermano mayor del crimen. Resalta en el cuento la situación de indefensión de las clases marginales que, aún siendo las víctimas de la violencia, tienen que soportar el descrédito derivado de una manipulación de la información que los relaciona siempre con el mundo de la delincuencia y los convierte siempre en culpables de las servidumbres sociales de la miseria.

\footnotetext{
Revista Iberoamericana, Vol. LXXVI, Núm. 230, Enero-Marzo 2010, 153-168 ISSN 0034-9631 (Impreso) ISSN 2154-4794 (Electrónico)
} 
Similares preocupaciones, pero con distintas perspectivas, en las que se conjuga la injusticia social con la discriminación, llevaría Cuti al teatro. En el monólogo en un acto titulado "Madrugada, me proteja!" Cuti presenta la otra cara de la realidad del afrobrasileño. En este caso no es la clase social a la que pertenece la que desencadena el conflicto, sino simple y puramente la raza. Estructurado con un planteamiento irónico, asistimos a una situación de carácter carnavalesco por la inversión de valores que muestra en la sociedad. El protagonista, afrobrasileño de la clase media, es atracado por un hombre blanco, el cual, además de humillarlo, le acusa de racista. El desenlace, aunque sea previsible, no es menos dramático e ilustrativo, ya que el asaltado es perseguido y detenido por la policía, transmitiendo un claro mensaje de que el hecho de ser negro le convierte automáticamente en un ser sospechoso. El robo y humillación a que es sometido el protagonista no es sino el trasunto de la humillación histórica que ha sufrido el negro en el Brasil.

Otra manifestación del racismo contra el que se rebela Cuti es la del mestizaje, entendido como una tendencia natural y positiva en la sociedad, cuando, en realidad, ha sido un proceso forzado y favorecido por la ideología del blanqueamiento, con un intenso componente racista. Lo contempla como una forma insidiosa de atacar la identidad del afrobrasileño y su rechazo hacia él quedará reflejado en el cuento “Quizila”, su narración más lograda, en la que se conjuga negritud, mestizaje y cultura para poner de relieve las inquietudes y rivalidades producidas en el propio seno de la comunidad negra y mulata. El cuento está centrado, de nuevo, en la clase media brasileña y estructurado en función de las dificultades surgidas para la creación de un centro cultural (Centro de Cultura Negra do Brasil) por parte de un grupo de intelectuales, primordialmente negros. En realidad, esta situación sirve como simple excusa para mostrar las desuniones, enfrentamientos e incomprensiones que dominan a la comunidad negra, representada por los dos principales protagonistas, Ronaldo y Ventura, y por el personaje mejor definido en el cuento, Jairo, un ser radicalizado que no encuentra otra solución a sus problemas que el recurso a la violencia. Es una narración en tercera persona, formalmente fragmentada como reflejo de la propia fractura del mundo negro brasileño. Fragmentación y enfrentamientos derivados de las angustias creadas en la comunidad negra por la propia complejidad racial del país y las dudas y dificultades para encontrar un lugar en una sociedad que los oprime y contribuye a separarlos ideológica, cultural y racialmente, convirtiéndolos en víctimas de la interiorización de los prejuicios racistas que les impiden autoafirmarse en su identidad y mantenerse unidos para crear un proyecto de futuro.

En su obra poética, Cuti incrementará la multiplicidad de matices con los que ha abordado el problema del racismo en su obra narrativa y teatral, partiendo de un enfoque apasionado y en ocasiones agresivo, una clara intencionalidad didáctica

Revista Iberoamericana, Vol. LXXVI, Núm. 230, Enero-Marzo 2010, $153-168$
ISSN 2154-4794 (Electrónico) 
y unos presupuestos con frecuencia utópicos, poniendo el énfasis en la temática de la identidad del afrobrasileño, la afirmación cultural y la explotación histórica. Tema, este último, desarrollado en el poema "Mamice”, en el que el poeta expresa su protesta ante el abuso al que ha sido sometido históricamente el pueblo negro, el cual pervive hasta nuestros días con formas de explotación más o menos encubiertas. Una vez establecido al comienzo del poema la imposibilidad de perdonar u olvidar por parte del poeta, "sou daqueles / que cobram o leite derramado" (38), lo finaliza clarificando una serie de aspectos que considera fundamentales para entender la rebeldía del afrobrasileño ante la deshumanización que ha sufrido como causa de esta explotación, al manifestar que su "vovó que não era vaca / morreu seca” y "seus bezerros brancos / agora touros desmamados / ainda procuram tetas / para seus rebentos viciados" (38). De esta forma tan gráfica, directa e incluso brutal, el recuerdo de sus antepasados es utilizado por el poeta para hacer una crítica de la tendencia histórica de las clases dominantes a degradar al afrobrasileño. Los "bezerros brancos" no son sino la actualización del proceso de explotación que ha dejado a la raza negra exhausta como resultado de un abuso perpetuo que incide en la idea de la insaciable avaricia del hombre blanco.

No podemos olvidar que el proceso de animalización del afrobrasileño ha sido una constante a lo largo de la historia con el objetivo de mostrar un ser inferior y justificar su postergación social. En todas las formas expresivas, tanto en la literatura como en las canciones y de forma gráfica en la pintura, se han manipulado sus rasgos o expresiones corporales hasta la deformación grotesca, o se le ha presentado en posturas o actitudes que inducían a esta percepción.

Una variante de este tema desarrollará Cuti en el poema "Belohorizontando" al ofrecer una perspectiva histórica de la esclavitud, en las que se engloba el recuerdo de los quilombos -símbolo de la rebeldía del pueblo negro- y sugerentes evocaciones poéticas de África y América: "muitas praias me afloram / na ida e na chegada / que em todo lugar tem mar / trazido por ancestrais / deixado pelas estradas”. En el poema, los viajes negreros y los inhumanos trabajos en la mina son evocados en una atmósfera de ensueño y recuerdos, en un contexto dominado por la riqueza metafórica que los carga de evocaciones al rememorar las miserias sufridas. El poema finaliza resaltando la angustia y la violencia de los recuerdos transmitidos por el sueño: "então galopo em meu sangue / a noite parida em raio / lasca de diamante / da negra minas gerais” (50).

Otro tema recurrente en Cuti es el de la autoafirmación, en el que se conjuga generalmente la defensa de su identidad y la de la estética negra. Esta afirmación identitaria, que se enfrenta al prejuicio y la tradición histórica, quedará reflejada en el poema "Ser negro", al mostrar el poder de resistencia y la capacidad de rebeldía del afrobrasileño como pueblo que ha sabido liberarse de una situación de miseria,

Revista Iberoamericana, Vol. LXXVI, Núm. 230, Enero-Marzo 2010, 153-168
ISSN 2154-4794 (Electrónico) 
abandono y sometimiento a la crueldad, realidades a las que se hace referencia a lo largo del poema, para transmitir un mensaje de esperanza y proyecto de futuro en sus versos finales, donde dice:

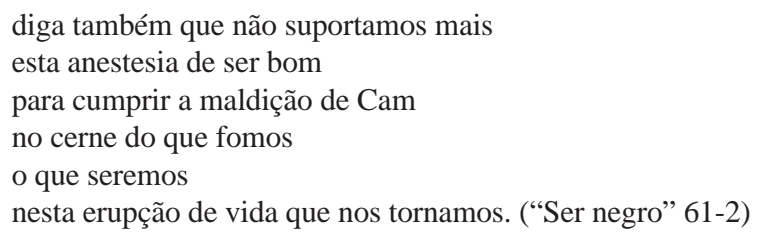

El tema de la cultura negra y su reivindicación, la búsqueda de sus elementos definidores y sus raíces, que situará en África -convertida en referente cultural a través de una visión idealizada y utópica en donde se centralizan y focalizan las energías generadoras- la búsqueda de modelos culturales adecuados para los nuevos tiempos y la preocupación por la pérdida de sus valores identitarios por el ataque constante de la cultura dominante, se constituyen en algunas de las más importantes preocupaciones de los miembros de Quilombhoje, y sobre el que ha incidido constantemente la obra de Cuti. Su poema "Cultura negra”, por su complejidad formal, preocupación innovadora y espíritu de rebeldía, es representativo de la importancia otorgada a la reivindicación de su cultura por parte del poeta. Estructurado en función de una serie de antítesis cromáticas con el objeto de resaltar la preponderancia que el color -es decir, la raza- tiene en la situación de subordinación cultural, enfatiza la opresión de la cultura blanca sobre el mundo negro, arrastrada desde la infancia, como expresa al comienzo del poema, al decir: "ariano afago / sobre a suposta acocorada / infância nossa” (34). El poeta se convierte en la voz de esa cultura "abrindo a porta enferrujada do silêncio" ante la oposición de la cultura blanca, que se resiste a esta irrupción cultural del afrobrasileño (34).

Uno de los grandes logros del grupo Quilombhoje es el de haber dado a las escritoras negras no sólo la posibilidad de dejar oír su voz, sino un indudable protagonismo. Su presencia y opiniones ofrecen la perspectiva del sector social que más ha sufrido la opresión en la sociedad brasileña y, aunque la temática tratada por ellas no difiera esencialmente de la de otros escritores del grupo, sí dejarán sentir su fuerza a la hora de defender ciertos posicionamientos que les afectan directamente, con clara definición feminista en Miriam Alves, o con un tono más moderado y conciliador en Esmeralda Ribeiro, quien en su novela corta, Malungos e milongas (1988), ha tratado la temática de la desunión de los negros, su debilidad como grupo y su vulnerabilidad como consecuencia de su dependencia socioeconómica y cultural de la clase dirigente blanca, desde una óptica femenina. La

Revista Iberoamericana, Vol. LXXVI, Núm. 230, Enero-Marzo 2010, $153-168$
ISSN 2154-4794 (Electrónico) 
claridad expositiva y la actitud de resistencia serán las características que dominan la obra narrativa de esta autora, la cual gira en torno a unos personajes femeninos de carácter firme y objetivos definidos. Su protagonista, Ruth, brillante joven negra, ve truncadas sus aspiraciones a ser ascendida a gerente en la empresa en que trabaja por rechazar las insinuaciones sexuales del presidente de la empresa, quien como venganza, enfrenta a ella con sus hermanos mediante unas maniobras en las que trata de aprovecharse de la ambición y la necesidad de la familia. Ruth, de fuerte personalidad, rebelde y sensata, que se mueve en un mundo hostil con seguridad, personifica la resistencia de la mujer negra a la explotación. Es la rebelión ante unas estructuras socio-económicas que favorecen el abuso y la división social, no sólo entre clases sociales sino también dentro de las propias comunidades raciales. La protagonista no se resigna a ser víctima de estructuras y comportamientos que degradan a la mujer. Su espíritu de rebeldía y su sinceridad marcarán un camino que siempre ha defendido Ribeiro: la mujer negra no podrá encontrar la libertad ni su puesto en la sociedad si no se enfrenta al sistema opresor, a lo que se añade el respeto a su cultura ancestral.

Con mayor dramatismo, pero con la misma intensidad, Ribeiro insiste en la transmisión del mensaje de rebeldía en su cuento “Guarde segredo”. El paralelismo con la narración anterior es claro. El acto de venganza llevado a cabo por la joven negra, protagonista del cuento, de acuchillar a su novio y a la madre de éste, ambos blancos, por las ofensas recibidas, transciende el propio hecho. Se transforma en la venganza de toda una raza, la negra, históricamente humillada por la clase poderosa blanca; de ahí el anonimato de la protagonista. De nuevo, el conflicto nace de la contraposición de los valores de dos mundos casi irreconciliables: el del afrobrasileño a la defensiva ante los ataques del hombre blanco dominador, que subyuga al mundo negro, poniéndose sobre todo de relieve en la opresión a la mujer por su doble característica de negra y mujer, convirtiéndola en un simple objeto sexual. Ribeiro juega con los excesos del prejuicio racial incitándonos a una reflexión sobre su carencia de fundamentos y sus trágicas consecuencias.

Como Cuti, Carlos de Assumpção trataría el tema de la esclavitud en una obra poética de enorme influencia en el desarrollo de la poesía negra: "Protesto" (50). Es un largo, intenso y clarificador poema, que se constituye en un alegato contra la esclavitud y un resumen de la historia de la opresión. Fue, sin duda, un punto de inflexión en el desarrollo de la poesía negra contemporánea, ampliamente comentado, entre otros, por Oubi Inaê Kibuko y Oswaldo de Camargo, y referente de toda la obra posterior en relación con este tema. Es un vivo y dramático recuerdo de la esclavitud y, ya en la década de los 60, cuando fue publicado, constituyó un llamado de atención sobre la pervivencia de las mismas estructuras y modos de opresión del pasado, aunque no fueran tan evidentes o reconocibles. Impregnado de un espíritu

Revista Iberoamericana, Vol. LXXVI, Núm. 230, Enero-Marzo 2010, 153-168
ISSN 2154-4794 (Electrónico) 
de rebelión y de rabia contenida, es un grito contra la discriminación y las injusticias cometidas contra el pueblo negro a lo largo de la historia y su proyección sobre el presente, y en el que el poeta establece un diálogo con el lector para decir que su lucha es la lucha de su pueblo. Como portavoz de su raza, el poeta se siente portador de una verdad, que tiene que ser comunicada, aunque es consciente de que nadie quiere oírla, ya que comienza el poema diciendo: "Mesmo que voltem as costas / às minhas palavras de fogo / Não pararei de gritar / Não pararei / Não pararei de gritar" (50). Es una verdad que molesta, que incomoda y tiene que comunicarse con cierta violencia y agresividad. Es el grito de una raza abandonada en un poema de protesta estructurado en función de un doble diálogo: con sus ancestros y con el pueblo brasileño. Con los primeros, dialoga:

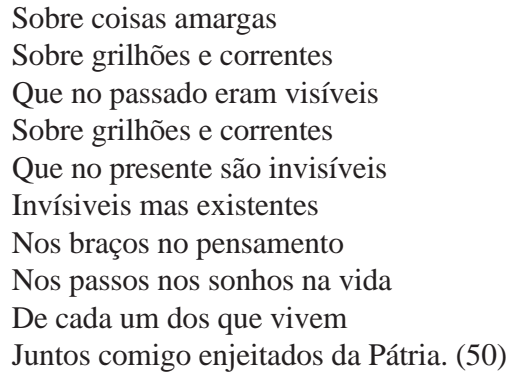

Estos versos, nos recuerda Kibuko, son fundamentales para entender las grandes mentiras que han dominado las relaciones sociales en el Brasil, difundidas y apoyadas por el mito de la democracia racial, que defiende la idea de que los blancos, indios y negros viven en armonía y que los problemas que puedan surgir en la sociedad brasileña son de tipo económico y, por lo tanto, solucionables, pero no de confrontación racial (Reflexões 78). La protesta se va a hacer más personal a medida que avanza el poema, al inscribir su rebeldía en la propia tradición familiar: "O sangue dos meus avós / Que corre nas minhas veias / São gritos de rebeldia" (Assumpção 50), y para expresar el drama y la angustia del afrobrasileño histórico, dice: "Sou eu aquele que se tornara / Vítima dos homens / Sou eu aquele que sendo homem / Foi vendido pelos homens” (51), en una atmósfera de connotaciones casi religiosas que nos retrotrae al contexto bíblico. Es decir, se siente privado de su humanidad al ser vendido como un "instrumento qualquer".

Toda esta crueldad se refuerza al continuar contraponiendo la realidad de opresión con sus aportaciones al desarrollo del país: "Sou eu aquele que plantara / Os canaviais e cafezais / E os regou com suor e sangue / Aquele que sustentou / Sobre os ombros negros e fortes / O progresso do país” (51); es la expresión de

Revista Iberoamericana, Vol. LXXVI, Núm. 230, Enero-Marzo 2010, 153-168
ISSN 2154-4794 (Electrónico) 
censura ante una realidad social que ignora deliberadamente la contribución del afrobrasileño a su progreso, oculta que es una parte esencial de la identidad del Brasil y desprecia su cultura. Su acusación y queja incluyen tanto el abuso histórico como la falta de justicia que nunca logró, para cerrar el poema con la misma idea del comienzo: "E nem a morte terá força / Para me fazer calar!” (53). El poeta expresa su convicción de que la sociedad escuchará este mensaje que nunca antes ha aceptado oír.

Si el poema "Protesto" marcó nuevos rumbos en la poesía negra, sobre todo por su densidad de contenido que resumía la inacabable sucesión de agravios históricos, "Escolha," de Oswaldo de Camargo, constituyó también un ejemplo representativo de una forma de hacer poesía definida por su belleza formal, rica simbología y un nuevo enfoque más tradicional y de mayor hondura:

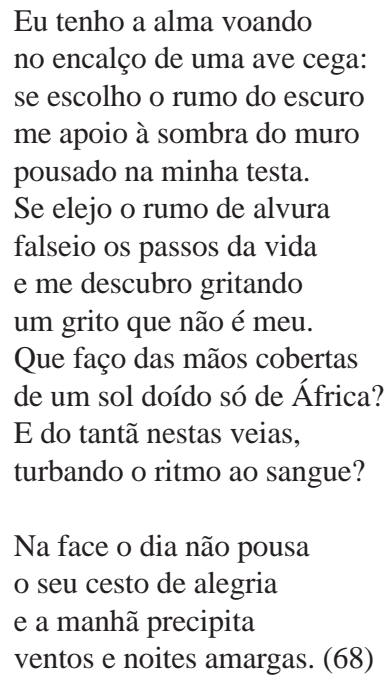

El símbolo del vuelo - eje central del poema- de tan rica tradición en la poesía de las lenguas española y portuguesa, reforzado por la carga simbólica de viento y ave, le comunica al poema una indudable espiritualidad y un gran poder de sugerencia. Esta asociación de símbolos que completan y matizan el concepto de alma remiten a lo transcendente, lo que combinado con el juego de contraposiciones crea la atmósfera adecuada para desarrollar el tema fundamental del poema, centrado en la angustia y el dolor del poeta ante la disyuntiva de elegir entre dos mundos que se oponen y a los cuales no se siente pertenecer. Dos universos que se contraponen no sólo a través de la simbología sino, sobre todo, mediante una serie

Revista Iberoamericana, Vol. LXXVI, Núm. 230, Enero-Marzo 2010, 153-168
ISSN 2154-4794 (Electrónico) 
de estructuras antitéticas: noche-día, negrura-alvura, alegría-tristeza, sol-sombra, que irán reforzando el significado básico de los símbolos, entre los que destacan, además de vuelo, el viento, el ave y el sol. Los tres primeros nos remiten, como señala J. C. Cooper, a las relaciones entre la espiritualidad y el mundo de las divinidades. El vuelo tiene un claro significado de "liberación del espíritu de las limitaciones de la materia” (Cooper 189), mientras que el ave, también asociado con lo espiritual, simboliza la capacidad para comunicarse con los dioses, sentido que se verá reforzado por la simbología de los vientos tradicionalmente considerados como los mensajeros de los dioses. Toda esta carga espiritual y positiva se verá contrarrestada por el principio negativo, a través de los símbolos de la noche y la sombra. Este juego de contrarios es una constante en el poema, que va agregando progresivamente significados a los sustantivos básicos como alma, efecto al que contribuye también la sobria adjetivación.

Esta simbología se asocia también al recuerdo de África, lo que le comunica a la poesía un tono nostálgico. La referencia a su tierra originaria se presenta en un contexto definido por otro símbolo clave: el sol, identificado con "la gloria, el esplendor y la justicia” (Cooper 168), y asimilado a valores positivos al representar la "fuerza heroica y generosa, creador y dirigente" (Cirlot 419) que ennoblece sus orígenes y sugiere el recuerdo del calor del hogar perdido. El poema finaliza con una sensación de desesperanza y fracaso, al sentirse el poeta incapaz de encontrar el rumbo a seguir.

Las obras de Cuti, Carlos de Assumpção, Oswaldo de Camargo y Esmeralda Ribeiro son ejemplos de la rica diversidad de enfoques, sensibilidades y preocupaciones que definen al grupo Quilombhoje, caracterizado también por un acentuado espíritu crítico, que les ha llevado a adentrarse en el estudio de la propia literatura negra, sus características, evolución y su situación real en el contexto de la literatura brasileña, sobre todo al constatar que más de un siglo después de la publicación del más importante poemario del siglo diecinueve, Broquéis (1893), del poeta negro Cruz e Sousa, todavía no hay seguridad sobre la plena consolidación de la literatura negra en el país. Aunque no existen dudas a la hora de afirmar la existencia de una literatura negra creativa y vital con características propias, no hay, sin embargo, tanta unanimidad cuando se trata de definir su función y el papel jugado en el desarrollo de la literatura brasileña.

Para Esmeralda Ribeiro, una de las características que definen esta literatura es el hecho de preocuparse por las realidades y necesidades auténticas del pueblo afrobrasileño, y señala que "Nossa literatura fala do camburão, da favela, da violência, de política. Enfim, coisas mais próximas da nossa realidade” ("Depoimento” 8). Para Márcio Barbosa lo que le comunica el rasgo distintivo es su subordinación a la literatura blanca y a su historia, y su especificidad vendrá determinada por

Revista Iberoamericana, Vol. LXXVI, Núm. 230, Enero-Marzo 2010, $153-168$
ISSN 2154-4794 (Electrónico) 
el hecho de ser "uma arte feita a partir de uma perspectiva do dominado, do oprimido" (50), y que surge con posterioridad a la existencia de una conciencia negra (51). Lino Guedes -sostiene Barbosa- será el punto inicial en la evolución de la literatura afrobrasileña tanto por su actitud de protesta como por su temática centrada específicamente en la historia del mundo negro (51). No obstante, coincide con Cuti en considerar a Solano Trindade un autor clave en la consolidación de esta literatura, situándolo como el primer gran poeta moderno por su oposición a las reglas conservadoras, su actitud política y por "sua recusa estética” (Barbosa 52), entendida ésta en un sentido amplio al considerarla "o rompimento não com a forma do poema simplesmente, mas com a forma da sociedade em si” (52), y, al encontrar su raíz africana y comprometerse con la evolución histórica de su pueblo.

Consciente de la pérdida de vitalidad que experimentaba la literatura negra desde la obra de Trindade, encuentra Barbosa en la década de los 70 el comienzo de una nueva recuperación que definirá, en realidad, lo que es la literatura afrobrasileña contemporánea en un proceso en el que se unen principalmente los jóvenes afrobrasileños con antiguos militantes de los movimientos negros, lo que les ofrece a los primeros la posibilidad de encontrar una nueva conciencia de ellos mismos (Barbosa 53) y al mismo tiempo les proporciona un sentido de unidad, precisamente en la "destruição daquilo que nega sua própria existência, quer seja a alienação, a falta de identidade” (Barbosa 53).

Los jóvenes recuperan así el espíritu de Trindade, que estableció su poesía sobre bases sociales y raciales, aunque este nivel debe ser superado porque ya no es una poesía que se oriente hacia afuera, sino que "é preciso que do exterior os poetas voltem-se para a sua interioridade e esse avanço é o que vai marcar a literatura negra contemporânea” (Barbosa 53). Se contempla la literatura como una expresión de la propia interioridad del negro y, además, como una forma de enfrentarse abiertamente, como subraya Minka, con todos aquellos mitos que de cualquier forma "engordaram o orgulho nacional do europeu-brasileiro e ajudaram a esculpir a máscara de democracia racial” (41).

Además de ser una literatura volcada hacia el interior del poeta, será combativa por haber nacido de la experiencia negra, y tendrá como uno de sus más importantes objetivos reescribir la historia, con el objeto de desterrar la imagen distorsionada que del afrobrasileño ha transmitido la literatura, recuperar sus héroes, reencontrar y revalorizar sus raíces africanas (Kibuko, "Depoimento”17). Es, por lo tanto, una literatura de resistencia porque, como ha puesto de relieve Francisco Mesquita, la literatura negra nace de la oposición a las condiciones reales de opresión en las que vive el negro y, aunque reconoce que "a literatura realmente não tem cor; o que existe são literatos negros ou brancos” (9), enfatiza el hecho de que cuando se habla de esta literatura en un país como el Brasil "onde a dominação é branca, reconhece-se uma função diferenciada da função da literatura dos países africanos” (9).

Revista Iberoamericana, Vol. LXXVI, Núm. 230, Enero-Marzo 2010, 153-168
ISSN 2154-4794 (Electrónico) 
El discurso poético de Quilombhoje trata de armonizar un mensaje reivindicador y combativo con la búsqueda denuevas formas expresivas acordes con la idiosincrasia del afrobrasileño. Esta búsqueda de nuevas formas está fundamentada en el hecho de considerar a la lengua portuguesa como poco idónea para transmitir las vivencias profundas del afrobrasileño al ser la lengua del opresor. Barbosa argumenta que la existencia de negros que escriben no garantiza la existencia de una literatura negra, ya que "as técnicas e a linguagem que usam são técnicas e linguagem brancas” (50).

Cuti insistirá en el mismo aspecto al indicar que la lengua portuguesa se ha usado para mantener al afrobrasileño en una situación de opresión (“Uma entrevista” 904), porque cristalizó todos los prejuicios y la ideología racista. Esto es muy importante porque refleja cómo este autor contempla su arma de trabajo, la lengua, que se va a convertir en arma de combate. Va a manipularla, como la ideología racista hiciera, pero en un sentido opuesto. Buscará nuevos significados, invertirá los existentes, cambiará la significación de los símbolos e incluso creará otros nuevos, a la vez que llenará las metáforas de un nuevo contenido y adaptará la estructura métrica a formas más acordes con la mentalidad y la concepción artística del mundo negro. Cuti, como otros muchos autores negros, trata por todos los medios de trastocar la carga ideológica de los términos. Se va a producir así una clara inversión de valores. Muchos medios expresivos, tan característicos de la poesía negra tanto en el contexto brasileño como en el hispánico, van a permanecer-como la aliteración, anáfora, estructuras antitéticas, paralelísticas o la preocupación por el ritmo-aunque se acentúe lo conceptual con recursos como la ironía, la parodia, la inversión carnavalesca, o el recurso de lo grotesco.

En el fondo se trata de lograr la máxima libertad expresiva, llevando al límite las posibilidades que ofrece el lenguaje, como muestra Marisa Trieta al comentar su proyecto poético: "Eu tenho um projeto de poesia negra sem o rigor da retórica. Este projeto constitui-se em desmembrar o português lógico. Provar o português misturado, usar da malícia, da bravura, da invenção. Reconstituir o pensamento truncado" (15). Es decir, busca la libertad total y, para lograr esto, no duda en "usar recursos simples como um jogo de capoeira, lindo como a cadência de samba. Reggear com os afoxés, funkar o rock, o blues, o samba-canção misto de emoção e deixar fluir a linha da internacionalização" (Trieta 15).

Esta sugerente y espontánea forma de hacer poesía es muy atractiva, pero muy difícil de llevar a cabo en la realidad. Si estudiamos la obra de Trieta, vemos que no logra plasmar tanta libertad ni tanta espontaneidad como ella aspira. El eclecticismo que caracteriza el uso del lenguaje del grupo Quilombhoje hace que sea difícil rastrear exactamente las raíces e influencias de cada autor, aunque habría que destacar como elementos claves el modernismo y concretismo, dos movimientos

Revista Iberoamericana, Vol. LXXVI, Núm. 230, Enero-Marzo 2010, $153-168$
ISSN 2154-4794 (Electrónico) 
literarios profundamente renovadores. El concretismo, al decantarse en la década de los 60 por lo social, enriqueciéndose con nuevos aportes temáticos, permitió que la temática negra encajara con facilidad en un movimiento que aporta una gran libertad a la hora de crear nuevas palabras, recrear otras, o apoyarse en la distribución espacial, las combinaciones fonéticas y visuales y la conversión del poema en un objeto visual para transmitir un mensaje de claro contenido racial.

Emanuelle Oliveira justifica el interés que muchos miembros del grupo, como Esmeralda Ribeiro y Márcio Barbosa, tuvieron por estos movimientos al recordarnos que el diálogo que establecieron con el modernismo y el concretismo tenía una triple justificación: por un lado, les proporcionaba la oportunidad de crear una poesía que permitía dar una visión crítica del canon brasileño. Por otro lado, la apropiación de las fuentes literarias suponía la estructuración de una estrategia "contra hegemónica”, para crear nuevos patrones de representación para la cultura afro-brasileña y, finalmente, le otorgaba un mayor nivel de legitimidad (Oliveira 138).

La verdad es que la solidez y coincidencia de criterios que encontramos en los aspectos ideológicos y temáticos del grupo se contraponen a la diversidad e inconsistencias de la estructura formal. Inconsistencias que frecuentemente entran en contradicción con su intento de encontrar una estructura formal propia.

En conclusión, los escritores de Quilombhoje han llevado a cabo el más completo esfuerzo por desmitificar las percepciones racistas del Brasil a la vez que han realizado un profundo análisis y valoración de todas las formas del racismo a nivel histórico y contemporáneo en ese país. Incluso, esta actitud analítica y divulgadora, profundamente didáctica, ha contribuido a desvalorizar la obra de algunos autores, como es el caso de Cuti.

Sus grandes aportaciones serán las de aglutinar, tanto formal como temáticamente, toda una tradición de literatura negra en el Brasil, aunque estén todavía inmersos en un proceso de búsqueda de un lenguaje propio, que sea auténtico y con el que se sientan plenamente identificados, objetivo no totalmente logrado. Por otro lado, su discurso no ha calado en el pueblo negro, pues se mueve en un mundo intelectual muy restringido o, tal vez, porque los procedimientos usados no han alcanzado la sofisticación o la adecuación del mensaje que se precisaba.

Quilombhoje se ha constituido en la voz crítica del mundo negro brasileño en el proceso de liberación de la alienación que históricamente lo ha definido, bien sea en forma de racismo, pobreza o ignorancia. En su obra, estos autores han tratado de encontrar un equilibrio entre la lucha reivindicativa en defensa de los valores y cultura negros, y la preocupación estética, partiendo de una perspectiva histórica que les permite elaborar un proyecto de futuro, aspecto claramente reflejado en el poema "Impasses e passos" (42), en el que Cuti se pregunta si el mundo negro

Revista Iberoamericana, Vol. LXXVI, Núm. 230, Enero-Marzo 2010, 153-168
ISSN 2154-4794 (Electrónico) 
seguirá en el silencio durante otros trescientos años, o si será capaz de elevar su voz para redimirse. Es decir, si será capaz de poner los medios para superar una situación real inaceptable que da validez a la conocida frase del intelectual brasileño Benedito Cintra: "Não é fácil ser negro num país de negros como o nosso" (16).

\section{OBRAs CITADAS}

Assumpção, Carlos de. "Protesto”. A razão da chama: Antologia de poetas negros brasileiros. Oswaldo de Camargo, org. São Paulo: Edições G. R. Dorea, 1986. 50-53.

Barbosa, Márcio. “Questões sobre a literatura negra”. Reflexões. Quilombhoje, org. São Paulo: Conselho de Participação e Desenvolvimento da Comunidade Negra, 1985. 50-56.

Camargo, Oswaldo de. "Escolha”. Poesia negra brasileira: Antologia. Zilá Bernd, org. Porto Alegre: Editora AGE, Instituto Estadual do Livro, 1992. 68.

Cintra, Benedito. "Negritude e arte.” Cadernos Negros: Os melhores poemas. Quilombhoje, org. São Paulo: Fundo Nacional da Cultura e Ministério da Cultura, 1998. 16.

Cirlot, Juan Eduardo. Diccionario de símbolos. Barcelona: Editorial Labor, 1985.

Cooper, J. C. Diccionario de símbolos. Barcelona: Editorial Gustavo Gili, 2000.

Cruz e Sousa, João da. Broquéis [1893]. Ed. e Prólogo Tasso de Silveira. Rio de Janeiro: Edições de Ouro, 1965.

Cuti [Luiz Silva]. "Quizila”. Quizila. São Paulo: Quilombhoje, 1987. 21-33.

“Ah, esses Jovens Brancos de Terno e Gravata!...”. Callaloo 18/4 (1995): 900.

“Madrugada, me proteja”. Callaloo 18/4 (1995): 893-99.

"Uma entrevista”. Callaloo 18/4 (1995): 901-04.

"Vida em dívida". Callaloo 18/4 (1995): 890-92.

"Cultura negra”. Cadernos Negros 19: Poemas afro-brasileiros. São Paulo: Quilombhoje; Editora Anita, 1996. 34.

"Mamice”. Cadernos Negros 19: Poemas afro-brasileiros. São Paulo: Quilombhoje; Editora Anita, 1996. 38.

“Belohorizontando”. Cadernos Negros 21. São Paulo: Quilombhoje; Editora Anita, 1998. 49-50.

“Impasses e passos”. Cadernos Negros 21. São Paulo: Quilombhoje; Editora

Anita, 1998. 42.

"Ser negro". Cadernos Negros 25. Esmeralda Ribeiro e Márcio Barbosa, orgs. São Paulo: Quilombhoje, 2002. 61-62.

Revista Iberoamericana, Vol. LXXVI, Núm. 230, Enero-Marzo 2010, 153-168
ISSN 2154-4794 (Electrónico) 
Freyre, Gilberto. Casa-grande e senzala: Formação da família brasileira sob o regime da economia patriarcal. Rio de Janeiro: José Olympio, 1973.

Gutiérrez, Gustavo. Teología de la liberación: perspectivas. Salamanca: Ediciones Sígueme, 1990.

Kibuko, Oubi Inaê. "Depoimento de autores”. Cadernos Negros 7. São Paulo: Quilombhoje, 1984.17.

“1955-1978: 23 Anos de Inconsciência”. Reflexões. São Paulo: Conselho de Participação e Desenvolvimento da Comunidade Negra, 1985. 70-86.

Mesquita, Francisco. "Depoimento de autores". Cadernos Negros 7. São Paulo: Quilombhoje, 1984. 9.

Minka, Jamu. "Literatura e consciência". Reflexões. São Paulo: Conselho de Participação e Desenvolvimento da Comunidade Negra, 1985. 38-56.

Oliveira, Emanuelle. Writing Identity: The Politics of Contemporary Afro-Brazilian Literature. West Lafayette, Indiana: Purdue UP, 2008.

Ribeiro, Esmeralda. Malungos e milongas. São Paulo: Quilombhoje, 1988. "Depoimento de autores". Cadernos Negros 7. São Paulo: Quilombhoje, 1984. 8.

“Guarde segredo". Cadernos Negros: Os melhores contos. São Paulo: Quilombhoje, 1998.65-72.

Ribeiro, Esmeralda, et. al., org. Cadernos Negros 21: Poemas afro-brasileiros. São Paulo: Quilombhoje; Editora Anita, 1998.

Trieta, Marisa. "Depoimento de autores”. Cadernos Negros 7. São Paulo: Quilombhoje, 1984.15.

ISSN 0034-9631 (Impreso) 